\title{
Notícia: VI Seminário Psicologia e Senso Religioso
}

\author{
Marta Helena de Freitas ${ }^{1}$ \\ Universidade Católica de Brasília
}

\section{News: VI Seminar Psychology and Religious Sense}

Organizado pelo Grupo de Trabalho Psicologia e Religião da ANPEPP - Associação Nacional de Pesquisa e Pós-Graduação em Psicologia, juntamente com o Programa de Pós-graduação em Psicologia da Pontifícia Universidade Católica de São Paulo, o VI Seminário Psicologia e Senso Religioso ocorreu em São Paulo, nos dias 24 a 26 de agosto de 2007, no Campus Paraíso, na Universidade Paulista - UNIP. A Comissão Organizadora do evento foi presidida por Marília Ancona-Lopez (PUCSP, UNIP), que procedeu à abertura do evento, juntamente com Geraldo José de Paiva (USP-SP), Coordenador do GT Psicologia \& Religião, da ANPEPP, o qual apresentou a principal estrela do evento - Prof. Mário Aletti, Presidente da Associação Italiana de Psicologia da Religião, psicanalista e docente da Universidade Católica de Milão, que proferiu a conferência de abertura intitulada "Cultura, religião e criatividade na vida adulta: rabiscos winnicottianos".

O evento, com cerca de 200 participantes, contou com oito grupos de trabalhos - GTs, quais sejam: 1) Transcrições Psíquicas da Experiência Religiosa, coordenado por Geraldo José de Paiva (USP) e José Paulo Giovanetti (UFMG); 2) Psicologia, Experiência Religiosa e Cultura, sob a coordenação de Miguel Mahfoud (UFMG); 3) Conflito Moral e Religiosidade: universos morais, valores definitivos e teorias de conflito, conduzido por James Reaves Farris (UMESP); 4) Atendimento terapêutico de Questões Religiosas, liderado por Gilberto Safra (PUCSP/ USP); 5) Aconselhamento Psicológico e Aconselhamento Espiritual, sob a responsabilidade de João Edênio dos Reis Valle (PUCSP) e Ronilda Iyakemi Ribeiro (USP / UNIP); 6) A Experiência Religiosa e os Psicólogos Clínicos: formação e exercício profissional, acompanhado por Mauro Martins Amatuzzi (PUCCAMP) e Marília Ancona-Lopez (PUCSP); 7) Práticas Religiosas e Corporeidade, coordenado por José Francisco Miguel Henriques Bairrão (USP); e 8) Linguagem, Símbolo e Mito na Sociedade Pós-secular: a fenomenologia hermenêutica e a experiência inter-religiosa, sob a responsabilidade de Olga Sodré (PUCRJ). Em cada GT, foram apresentados seis a oito trabalhos, seguidos de debate; e cada um dos coordenadores, apresentou, na manhã do dia 26, uma síntese do conjunto, caracterizando-se o compartilhamento com os integrantes dos demais GTs.

1 Endereço: SHCGN 716, Bl C, Casa 30, Brasília, DF, Brasil 70.770730.E-mail:mhelena@ucb.br
Ao longo do evento foram também proferidas três significativas palestras: "Aconselhamento psicológico e espiritualidade", por Yolanda Cintrão Forghieri (USP/ PUCSP); "Em busca da transcendência perdida: Carlos Drummond de Andrade e uma página de Proust", por Waldecy Tenório (USP); e, como palestra de encerramento, "A psicologia e as novas religiões em uma sociedade pluralista", por Mário Aletti.

Os temas desenvolvidos no VI Seminário Psicologia e Senso Religioso se deram em continuidade a um trabalho de reflexão sobre as relações entre Psicologia e Religião, iniciado em 1997, em Ribeirão Preto, com a realização do I Seminário. A partir de então, o evento vem sendo realizado a cada dois anos, resultando em publicação de livros com os temas tratados em cada Seminário, conforme referências completas apresentadas ao final desta notícia.

Na sua sexta edição, outra novidade do Seminário, além da constituição dos oito GTs, foi o ciclo de conferências sobre "Psicologia, Religião e Espiritualidade", realizadas em Brasília-DF, nos dias 20 a 22 de agosto de 2007, nos Campi da Universidade Católica de Brasília - UCB, e da Universidade de Brasília - UnB, sob a organização de Norberto Abreu e Silva Neto (UnB), Marta Helena de Freitas (UCB) e José Lisboa Moreira de Oliveira (UCB). As conferências foram proferidas por Mário Aletti e debatidas por Geraldo José de Paiva e Norberto de Abreu e Silva Neto, e versaram os seguintes temas: "A psicologia frente à religião e à espiritualidade: questões de conteúdo e de método", "Novas formas de religiosidade na cultura pósmoderna" e "Atendimento psicológico e direção espiritual: semelhanças, diferenças, integração e confusões".

As atividades em torno de tema ainda tão silenciado no contexto da formação e da pesquisa em Psicologia permitiram aos participantes do VI Seminário Psicologia e Senso Religioso levarem consigo, ao final do evento, a esperança e a expectativa de que os desafios colocados pelo assunto sejam cada vez mais assumidos pela comunidade científica e reconhecidos como estímulo à revisão crítica das potencialidades e dos limites dos discursos psicológicos e de seus fundamentos epistemológicos. Aguardemos, então, a publicação - já a caminho - das palestras, conferências e trabalhos apresentados no Seminário, a exemplo das que resultaram de suas versões anteriores:

1) Massimi, M. e Mahfoud, M. (Orgs.) (1999). Diante do mistério: psicologia e senso religioso. São Paulo: Loyola. (II Seminário, realizado na UFMG - BH).

2) Paiva, G. J. (Org.) (2000). Entre a necessidade e o desejo: diálogos da psicologia e da religião. São Paulo: Loyola. (III Seminário, realizado na USP - SP). 
3) Paiva, G. J. e Zangari, W. (Orgs.) (2004). A representação na religião: perspectivas psicológicas. São Paulo: Loyola. (IV Seminário, realizado na USP - SP).

4) Amatuzzi, M. M. (Org.) (2005). Psicologia e espiritualidade. São Paulo: Paulus. (V Seminário, realizado na PUC - Campinas).
Recebido em 30.08.2007

Aceito em 30.08.2007 